\title{
DEMANDA HÍDRICA PARA IRRIGAÇÃO POR PIVÔS CENTRAIS NO ESTADO DE GOIÁS
}

\author{
WATER DEMAND FOR IRRIGATION CENTRAL PIVOTS IN STATE OF GOIÁS
}

\author{
DEMANDA DE AGUA PARA RIEGO CON PIVOTES CENTRALES \\ EN ESTADO DE GOIÁS
}

\author{
Lindolfo Caetano Pereira Júnior - Instituto Mauro Borges de Estatísticas \\ e Estudos Socioeconômicos - Goiânia - Goiás - Brasil \\ lindolfo-cpj@segplan.go.gov.br \\ Patrícia Pereira da Silva Nicácio - Instituto Mauro Borges de Estatísticas \\ e Estudos Socioeconômicos - Goiânia - Goiás - Brasil \\ patricia-psn@segplan.go.gov.br
}

\begin{abstract}
Resumo
Este trabalho traz um balanço entre a oferta e a demanda hídrica para a irrigação por pivôs centrais em Goiás. Para tal, foram considerados os equipamentos existentes em 2013 no estado e no Distrito Federal. A disponibilidade hídrica considerada foi o volume outorgável para cada mês do ano no estado de Goiás: $50 \%$ da $095 \%$, e, para 0 cálculo da demanda, utilizaram-se os procedimentos definidos no Manual Técnico de Outorga da Secretaria do Meio Ambiente e Recursos Hídricos (Semarh). Nesse contexto, foram delimitadas 9.542 sub-bacias, das quais 2.850 apresentaram demanda no ano de 2013 , e destas, 543 tiveram demanda superior ao volume outorgável. Observou-se que o período que apresentou maior demanda foi entre abril e setembro, figurando este último mês como o mais crítico. Mapearam-se ainda oito áreas que apresentaram um elevado índice de comprometimento, sobretudo nas regiões do Alto e Médio Paranaíba, Médio Araguaia e Alto Rio Uru, além da Bacia do Rio Preto, predominantemente no Distrito Federal.
\end{abstract}

Palavras-chave: irrigação, pivôs centrais, disponibilidade hídrica, comprometimento hídrico.

\section{Abstract}

This work brings a balance between supply and water demand for irrigation by central pivots in Goiás. The analysis considered the facilities of Goiás and the Distrito Federal in 2013. The water availability considered were the granted volume for each month of the year in Goiás: $50 \%$ of $095 \%$.To calculate the demand were used the procedures defined in the Technical Manual for the Granting of SEMARH. In this context, it was delimited 9,542 sub-basins of which 2,850 has demand in 2013 , of which 543 had demand superior to the granted volume. It was observed that the period that presented the highest demand was between April and September, figuring this last month as the most critical. Eight areas that showed high levels of commitment were mapped, especially in the Upper and Middle Paranaíba, Middle River Araguaia and Upper River Uru, beyond the River Preto basin's, predominantly in the Distrito Federal.

Key words: irrigation, center pivots, water availability, water impairment.

\section{Resumen}

Este trabajo constituye el equilibrio entre la oferta y demanda de agua para riego por pivotes centrales em Goiás. Considerandose, para estos, las instalaciones existentes, en 2013, en el estado de Goiás y el Distrito Federal. La disponibilidad de agua considerada fue el volumen otorgable para cada mes del año en el estado de Goias: $50 \%$ de $095 \%$. Para el cálculo de la demanda se utilizaron los procedimientos definidos en el Manual Técnico para Otorga de la SEMARH. En esto contexto, 9.542 subcuencas de los cuales 2.850 tenían demanda en 2013 y de ellos 543 tenían mayor que la demanda de volumen otorgable. Se observó que el período de mayor demanda fue 
entre abril y septiembre, calculando este último mes como el más crítico. Fueran assignados aún ocho áreas que tenían un alto nivel de compromiso, especialmente en el alto y medio Paranaíba, Medio Río Araguaia y Alto Río Uru, adicionalmente la cuenca del Río Preto, en su mayor parte en el Distrito Federal.

Palabras clave: riego, pivotes centrales, disponibilidad de agua, compromiso del agua.

\section{Introdução}

A água tem um papel fundamental no desenvolvimento econômico e social mundial (Rodrigues; Pereira, 2009), e sua utilização vem crescendo de forma acelerada nas últimas décadas. No século 20, o consumo mundial de água mais que triplicou, passando de $1.382 \mathrm{~km}^{3} \mathrm{a}^{-1}$ em 1950 para $3.973 \mathrm{~km}^{3} \mathrm{a}^{-1}$ no fim do século, e a projeção de consumo até 2025 é da ordem de $5.235 \mathrm{~km}^{3} \mathrm{a}^{-1}$ (Clarke; King, 2004). Segundo a Fundação das Nações Unidas para Alimentação e Agricultura (FAO), esse consumo encontra-se dividido da seguinte forma no planeta: 70\% para irrigação, $20 \%$ para atividades industriais e 10\% para usos urbanos (ONU, 2014).

No Brasil, a vazão total consumida no ano de 2010 foi da ordem de $1.161 \mathrm{~m} 3 \mathrm{~s}-1$, dos quais $72 \%$ para irrigação, 11\% para dessedentação animal, 9\% para abastecimento humano urbano, $7 \%$ para uso industrial e $1 \%$ para abastecimento humano rural, conforme dados da Agência Nacional de Água (ANA) (Brasil, 2013). Em Goiás, nesse mesmo ano, a demanda total dos usos consuntivos foi de 192,02 m3s-1, o que representa 8,09\% da demanda nacional. Assim como nos cenários brasileiro e mundial, o uso consuntivo mais expressivo é para irrigação, que representa $66 \%$ da demanda goiana, seguido pelo uso industrial, com 19\%; o uso urbano, com 8\%; e a dessedentação animal, com 7\%, ainda conforme dados da ANA (Brasil, 2013).

Apesar da grande demanda hídrica exercida pela irrigação no planeta, essa técnica agrícola tem um papel fundamental para a segurança alimentar mundial (Varis, 2007). Fraiture e Wichelns (2010) deixam claro que o crescimento da população e o desenvolvimento econômico mundial têm contribuído de forma considerável para o aumento da demanda por alimentos, o que resulta no crescimento também da demanda hídrica. Neste contexto, os mesmos autores tratam a questão da escassez hídrica como notadamente crítica para a segurança alimentar mundial.

No Brasil, a pressão exercida sobre as reservas hídricas é cada dia maior, em virtude, principalmente, da demanda agrícola e da geração de energia por meio de hidroelétricas. O país conta atualmente com uma taxa 
de urbanização de 84,36\% (IBGE, 2010), bastante superior às médias mundiais que, segundo o Fundo de População das Nações Unidas (UNFPA), giram em torno de 50\% (ONU, 2011). Atrelado a isso, o país possui uma atividade agrícola intensa, que representa 5,3\% do Produto Interno Bruto (PIB) nacional (IBGE, 2012), e conta com um setor elétrico, composto primordialmente por usinas hidroelétricas, que é altamente vulnerável às condições hidrológicas (GUEDES FILHO, 2003).

Goiás, neste cenário, apresenta-se como um dos estados mais vulneráveis à conservação dos recursos hídricos, o que ocorre, sobretudo, em função de a agropecuária ser uma das atividades basilares da economia goiana. No ano de 2011, o setor agropecuário teve participação de 12,5\% no PIB do estado, com expansão de 14,1\% em relação a 2010, conforme o Instituto Mauro Borges (IMB), da Secretaria de Gestão e Planejamento do Estado de Goiás (Goiás, 2013a). O setor elétrico também exerce enorme pressão sobre os recursos hídricos, uma vez que 8,6\% (11.170 MW) da geração elétrica nacional tem origem no estado de Goiás. Vale destacar que, desse total, $9.561 \mathrm{MW}$, ou seja, 86\%, são oriundos de hidroelétricas, segundo a Secretaria de Infraestrutura do Estado de Goiás (Seinfra) (Goiás, 2013b).

Associado a esses fatos, ressalta-se que o estado abriga em seu território as nascentes de três grandes bacias nacionais: Araguaia/Tocantins, Paraná e São Francisco (Nascimento, 1992; Eiten,1993; Teixeira Neto, 2013). Deste modo, a gestão hídrica goiana exerce forte influência sobre diversas unidades da federação.

Tucci, Hespanhol e Cordeiro Netto (2000) enfatizam que o ponto-chave da gestão hídrica encontra-se no monitoramento hidrológico. No Brasil, essa ação concentra-se em entidades federais com atribuições que envolvem o território extenso, por conseguinte, as bacias de pequeno porte, essenciais para o gerenciamento das demandas hídricas, quase não são monitoradas. O estado de Goiás é um exemplo dessa realidade, visto que não há uma rede estadual de monitoramento e as estações que se encontram em atividade, geridas em sua maioria pela ANA, apresentam área de drenagem superior a $1.000 \mathrm{~km}^{2}$.

\section{Caracterização da área de estudo}

O Centro-Oeste brasileiro, onde estão inseridas as áreas em estudo - Goiás e Distrito Federal -, apresenta-se como uma região de dispersão 
de águas. Tal característica é resultante do soerguimento do Escudo Brasileiro, ocorrido na Era Paleozoica. Uma característica peculiar da região é a proximidade das vertentes de diferentes bacias hidrográficas, possibilitando a formação de "águas emendadas", fenômeno atribuído à suavidade das linhas divisórias de águas resultantes das superfícies acentuadamente aplainadas (IBGE, 1988).

A morfologia da área é caracterizada pelo predomínio de rios de planalto, com a presença de algumas quedas d'água e diversos acidentes de menor vulto, como corredeiras e travessões. Outra característica que merece destaque é a sua capacidade armazenadora, que está relacionada com a predominância de solos permeáveis e com a topografia suave, que retardam o escoamento da água e propiciam elevado índice de infiltração (IBGE, 1988).

O território goiano possui clima quente e úmido e apresenta duas estações bem definidas, uma seca (abril a setembro) e a outra chuvosa (outubro a março), com precipitação média anual entre 1200 e $1800 \mathrm{~mm}$ (Marcuzzo; Faria; Pinto Filho, 2012). O estado é banhado por três bacias hidrográficas: a do Rio Tocantins, a do Rio Paranaíba e a do Rio São Francisco (Figura 1). Esta última cobre menos de 1\% do território goiano e conta com 125 pivôs centrais, enquanto no Distrito Federal estão instalados 190 equipamentos. Já a bacia do Rio Paranaíba cobre 44\% da área do estado e abriga a maior parte da população goiana, aproximadamente $75 \%$, e, além disso, conta com a maioria dos equipamentos instalados em Goiás, totalizando 2.141 unidades (Goiás, 2014c).

As bacias dos rios Araguaia e Tocantins, já no noroeste e norte do estado, respectivamente, cobrem juntas aproximadamente 55\% do território goiano e possuem 654 equipamentos instalados. Esses dados retratam a configuração da irrigação por pivôs centrais na área de estudo, que possui 3.110 equipamentos, dos quais 2.897 estão em Goiás e 213, no Distrito Federal. Neste último, é possível observar que a intensa urbanização de suas regiões central, sudoeste e noroeste forçaram a fixação da agricultura nas regiões sudeste e nordeste, sobretudo na bacia hidrográfica do Rio Preto, como pôde ser observado na Figura 1. 


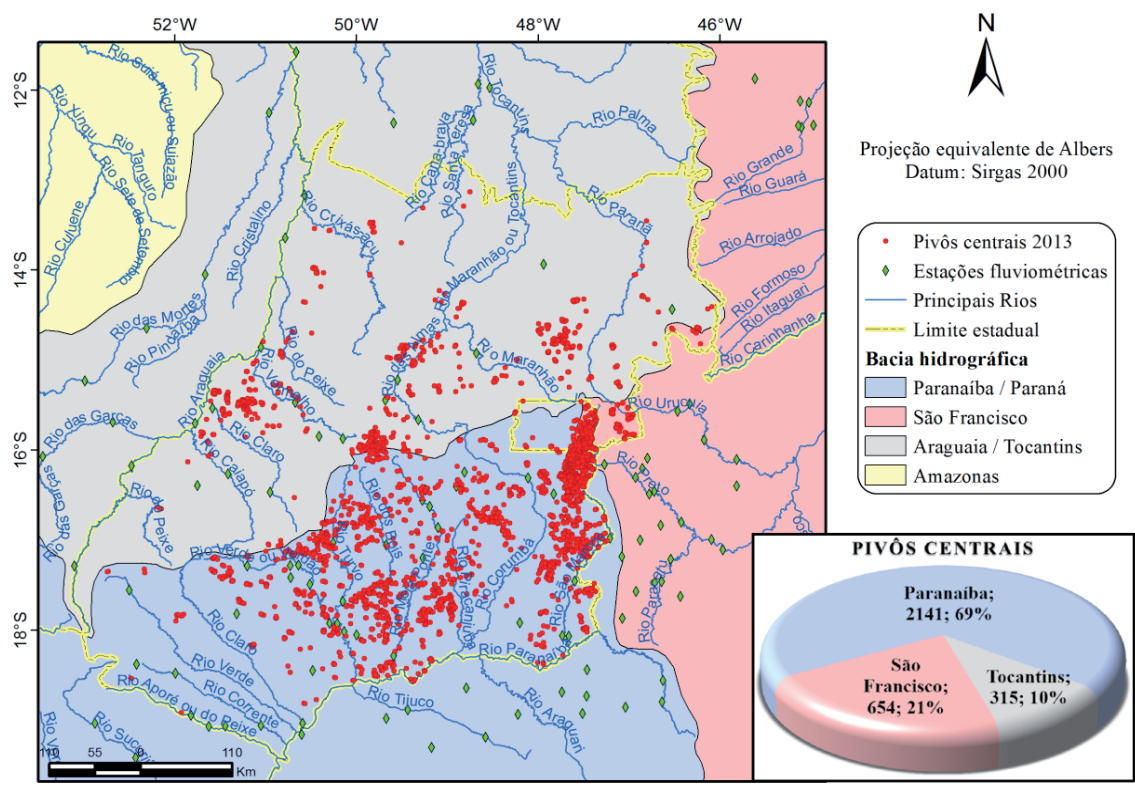

Figura - Localização da área de estudo com indicativo das estações fluviométricas e pivôs centrais

Fonte: Adaptado pelos autores, com base em Goiás (2014c) e Brasil (2006).

\section{Metodologia}

A definição de áreas críticas, no que tange à quantidade de água, passa obrigatoriamente pela realização do balanço entre oferta e demanda, ou seja, a relação entre o que entra e o que sai de água em uma determinada bacia hidrográfica. Assim sendo, esse cálculo depende da definição da disponibilidade hídrica e também da estimativa da demanda. Além disso, é necessária a delimitação das bacias hidrográficas, que são o recorte espacial de definição dos cálculos.

Para este artigo, os cálculos foram realizados em quatro grandes etapas: delimitação das bacias hidrográficas; definição da disponibilidade hídrica; identificação da demanda hídrica; e balanço entre oferta e demanda. Não foram considerados os barramentos (acumulações hídricas voltadas à irrigação, geração de energia, dessedentação de animais, entre outros) existentes no estado de Goiás e no Distrito Federal. Essa decisão 
deve-se, sobretudo, à falta de dados acurados a respeito dessas acumulações hídricas, o que inviabiliza a modelagem das suas capacidades de suporte. Sabe-se que a falta de modelagem dos reservatórios prejudica a definição da real capacidade de uma bacia hidrográfica, mas isso não interfere neste trabalho, cujo objetivo é mapear as áreas com elevado potencial de disputa hídrica, identificando as que são prioritárias para intervenções em escala local, a qual permite a modelagem dos barramentos.

\section{Delimitação das bacias hidrográficas}

O primeiro passo para a realização deste trabalho foi a delimitação de sub-bacias hidrográficas em todo o território goiano e também no Distrito Federal. Essa atividade foi realizada com a aplicação do TauDem (Terrain Analysis Using Digital Elevation Models), um modelo de delimitação de bacias hidrográficas que permite, entre outros, a geração de hierarquia entre elas. Essa característica viabiliza a análise de trechos recursivamente e permite avaliar cada um deles de três formas: individual, ou seja, sem considerar contribuições; considerando as contribuições de montante, isto é, o déficit ou o excedente recebido pelo trecho; e a sua contribuição, déficit ou excedente, que segue para jusante.

Nesse contexto, foram delimitadas 9.542 sub-bacias em todo o estado de Goiás e no Distrito Federal, com área média de $36,5 \mathrm{~km}^{2}$, sendo que as menores áreas mapeadas possuem aproximadamente $0,11 \mathrm{~km}^{2}$, e as maiores, até $340 \mathrm{~km}^{2}$. No que tange aos trechos de drenagem, foram gerados 10.627 segmentos, com comprimento médio de $6,7 \mathrm{~km}$, chegando até $65 \mathrm{~km}$. A Figura 2 a seguir exemplifica como ficaram delimitados os trechos e também as sub-bacias hidrográficas.

O processo de delimitação das bacias teve como premissa básica segmentar a drenagem em níveis que permitissem a análise de pequenos trechos de rios. Tal processo possibilitou a definição das áreas que se encontram sobrecarregadas pela utilização de pivôs centrais, uma vez que a análise macro poderia subestimar o impacto desses equipamentos em um determinado segmento de rio. Essa delimitação foi realizada a partir de imagens SRTM (Shuttle Radar Topography Mission), que possuem resolução espacial de 90 metros para o Brasil. Esses dados possuem uma precisão altimétrica em torno de 16 metros, o que possibilita a delimitação de bacias hidrográficas de forma adequada aos objetivos deste trabalho. 


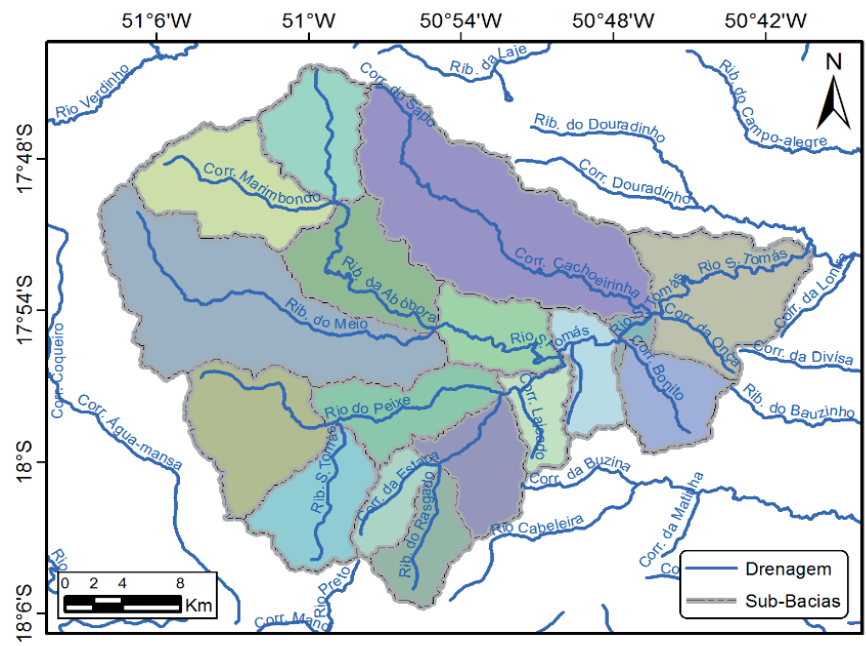

Figura 2 - Representação dos trechos de drenagem e das sub-bacias no Rio São Tomaz, localizado no município de Rio Verde e afluente do Rio Verde ou Verdão Fonte: Elaborado pelos autores.

Definição da disponibilidade hídrica

Para o cálculo da disponibilidade hídrica foram utilizados os dados de vazão de 115 estações fluviométricas com séries superiores a 20 anos, situadas nos estados de Goiás, Minas Gerais, Bahia, Tocantins, Mato Grosso e Mato Grosso do Sul. Esses dados são disponibilizados pela ANA, por meio do hidroweb, que é um sistema de informações hidrológicas (Brasil, 2006).

Procedeu-se então o cálculo da vazão específica para cada estação e posteriormente realizou-se a interpolação desses valores por meio do método IDW (Inverse Distance Weighted), definindo, dessa forma, a vazão específica de todo o território goiano e do Distrito Federal. Tal cálculo foi realizado para cada mês do ano, com o objetivo de viabilizar a análise mensal da oferta de água.

A vazão média específica de cada sub-bacia pôde então ser definida, o que possibilitou, também, o cômputo da vazão máxima outorgável e, consequentemente, o volume máximo outorgável para cada mês do ano, conforme Equação 1 a seguir. A outorga de direito de uso de recursos 
hídricos é um dos seis instrumentos da Política Nacional de Recursos Hídricos, instituída pela Lei Federal no 9.433, de 8 de janeiro de 1997 (Brasil, 1997). Trata-se de um instrumento que objetiva assegurar o controle quantitativo e qualitativo dos usos da água e o efetivo exercício dos direitos de acesso aos recursos hídricos.

$$
\frac{\frac{Q 95}{2} * 86400 * \text { dias do mês } * \text { Área }\left(\mathrm{km}^{2}\right)}{1000} \quad \text { (Equação 1) }
$$

O cálculo do volume fez-se necessário, sobretudo em função da falta de informações a respeito dos sistemas de captação utilizados pelos pivôs centrais mapeados. Dessa forma, foi considerado o volume mensal máximo outorgável de cada sub-bacia.

Definição da demanda hídrica

Para a realização do cálculo da demanda hídrica foi utilizada metodologia instituída pelo Manual Técnico de Outorga da Secretaria do Meio Ambiente e dos Recursos Hídricos de Goiás (Semarh) de 2012 (Goiás, 2012), que utiliza como referência as equações propostas pela FAO/AGLW (Dastane, 1978) e USDA/SCS (Smith, 1988) para o cálculo da precipitação média provável e da precipitação efetiva provável, respectivamente. Para aplicação dos cálculos foram utilizados os dados de precipitação e evapotranspiração contidos no programa LocClim v2. Foram exportados do programa 7.800 pontos em uma malha que cobriu todo o território goiano.

A partir desses dados foram aplicados os cálculos para cada ponto, chegando-se à Precipitação Média Provável (PMP) e à Precipitação Efetiva Provável (PP \%). Além disso, foi estimada a evapotranspiração para o estado, com base nos valores de referência das culturas de soja, milho e feijão, cultivos que foram escolhidos por sua representatividade na produção agrícola goiana. Conforme dados do IMB (Goiás, 2014b), a soja e o milho são as principais commodities produzidas em Goiás, que possui ainda a terceira maior produção de feijão do país. A partir disso, foi necessário apenas acrescentar a eficiência do sistema - que no caso dos pivôs centrais é de $80 \%$-, para que fosse possível chegar aos valores de demanda por hectare para cada um dos 7.800 pontos citados.

A partir da demanda gerada para cada ponto foi realizada a interpolação, pelo método do vizinho mais próximo, para cada mês do ano, o que 
originou doze arquivos do tipo raster. Essas imagens possuem resolução espacial de 90 metros - característica que as tornam compatíveis com o modelo digital de terreno (SRTM) utilizado na delimitação das bacias - e representam a demanda por hectare de cada mês do ano de 2013.

A última parte do cálculo da demanda foi o cruzamento entre a localização dos 2.897 pivôs centrais em Goiás (Goiás, 2014c) e dos 213 no Distrito Federal, que foram mapeados para este trabalho, e as demandas mensais por hectare de cada pivô. Assim, sabendo-se a área de cada equipamento e sua demanda por hectare, foi possível definir a demanda mensal de cada equipamento para os doze meses do ano. Isso possibilitou a obtenção do volume máximo mensal necessário para cada equipamento.

O passo seguinte foi a definição da demanda de cada uma das 9.542 sub-bacias anteriormente delimitadas, que foi realizada em ambiente de Sistema de Informações Geográficas (SIG). Executou-se, então, o cruzamento entre as sub-bacias e a demanda dos pivôs centrais, o que possibilitou a definiçãa da demanda mensal de cada sub-bacia.

\section{Balanço entre oferta e demanda}

O balanço entre a oferta e a demanda hídrica dividiu-se em duas fases. Na primeira definiu-se a situação de cada sub-bacia, a partir da utilização dos dados de oferta e demanda, realizando-se a subtração entre o volume máximo outorgável, calculado por meio da Equação 1, e o volume máximo mensal necessário em cada segmento. Essa fase refere-se à análise individual de cada trecho de drenagem.

Na segunda etapa, foi realizado o cálculo das contribuições, ou seja, foi feita a análise dos resultados obtidos na primeira etapa de montante para jusante, possibilitando mensurar a contribuição de cada sub-bacia a montante de um determinado ponto. Esse cálculo viabilizou a análise do comprometimento a montante e a jusante. Vale ressaltar que a Resolução nº 9/2005, do Conselho Estadual de Recursos Hídricos (Goiás, 2005), preconiza a análise apenas a montante de determinado ponto, não sendo verificados os impactos do uso a jusante, o que pode ser prejudicial à gestão hídrica das bacias hidrográficas.

Ressalta-se que o balanço realizado não considerou os barramentos existentes, sobretudo pela falta de informações dos volumes úteis. Vale destacar, ainda, que este trabalho visa a mapear as áreas prioritárias, para 
que, em trabalhos posteriores, sejam realizadas análises mais detalhadas e que contenham, inclusive, a modelagem desses barramentos, para verificar sua real capacidade de regularização das vazões e atendimento das demandas dos equipamentos que as utilizam.

\section{Resultados e discussões}

Os dados de comprometimento hídrico da área de estudo são inversamente proporcionais ao período chuvoso. A Tabela 1 demonstra que a partir do mês de março se inicia um processo de aumento da demanda hídrica no estado, e que a partir de abril existe a definição dos trechos que possuem alguma demanda de irrigação. Nesse contexto, 2.850 trechos apresentam demanda no período de estiagem. Fica claro que existe um aumento da demanda até o mês de setembro, quando o número de áreas consideradas altamente críticas chegou a 543.

Tabela 1 - Demanda por sub-bacia

\begin{tabular}{|c|c|c|c|c|c|c|c|c|c|c|c|c|}
\hline COMPROMETIMENTO* & JAN & FEV & MAR & ABR & MAI & JUN & JUL & AGO & SET & OUT & NOV & DEZ \\
\hline Sem demanda & 9.435 & 9.409 & 8.978 & 6.692 & 6.692 & 6.692 & 6.692 & 6.692 & 6.692 & 6.709 & 9.409 & 9.472 \\
\hline De $0,01 \%$ a $50 \%$ & 107 & 133 & 561 & 2.773 & 2.525 & 2.383 & 2.187 & 1.990 & 1.974 & 2.596 & 133 & 70 \\
\hline De $51 \%$ a $80 \%$ & - & - & 2 & 45 & 151 & 203 & 256 & 222 & 222 & 96 & - & - \\
\hline De $81 \%$ a $100 \%$ & - & - & - & 14 & 53 & 76 & 94 & 125 & 111 & 55 & - & - \\
\hline De $101 \%$ a $200 \%$ & - & - & 1 & 17 & 88 & 137 & 198 & 301 & 294 & 60 & - & - \\
\hline Maior que $200 \%$ & - & - & - & 1 & 33 & 51 & 115 & 212 & 249 & 26 & - & - \\
\hline TOTAL & 9.542 & 9.542 & 9.542 & 9.542 & 9.542 & 9.542 & 9.542 & 9.542 & 9.542 & 9.542 & 9.542 & 9.542 \\
\hline
\end{tabular}

Fonte: Elaborada pelos autores.

A Figura 3 a seguir traz duas áreas irrigadas distintas, localizadas nos municípios de Paraúna e Cristalina, respectivamente. A área de Paraúna, que ainda não tem a predominância de pivôs centrais, passou por um crescimento significativo na última década, saindo de 38 equipamentos no ano de 2000 para 116 em 2014. Na área do município de Cristalina, predomina a irrigação por pivôs centrais. 


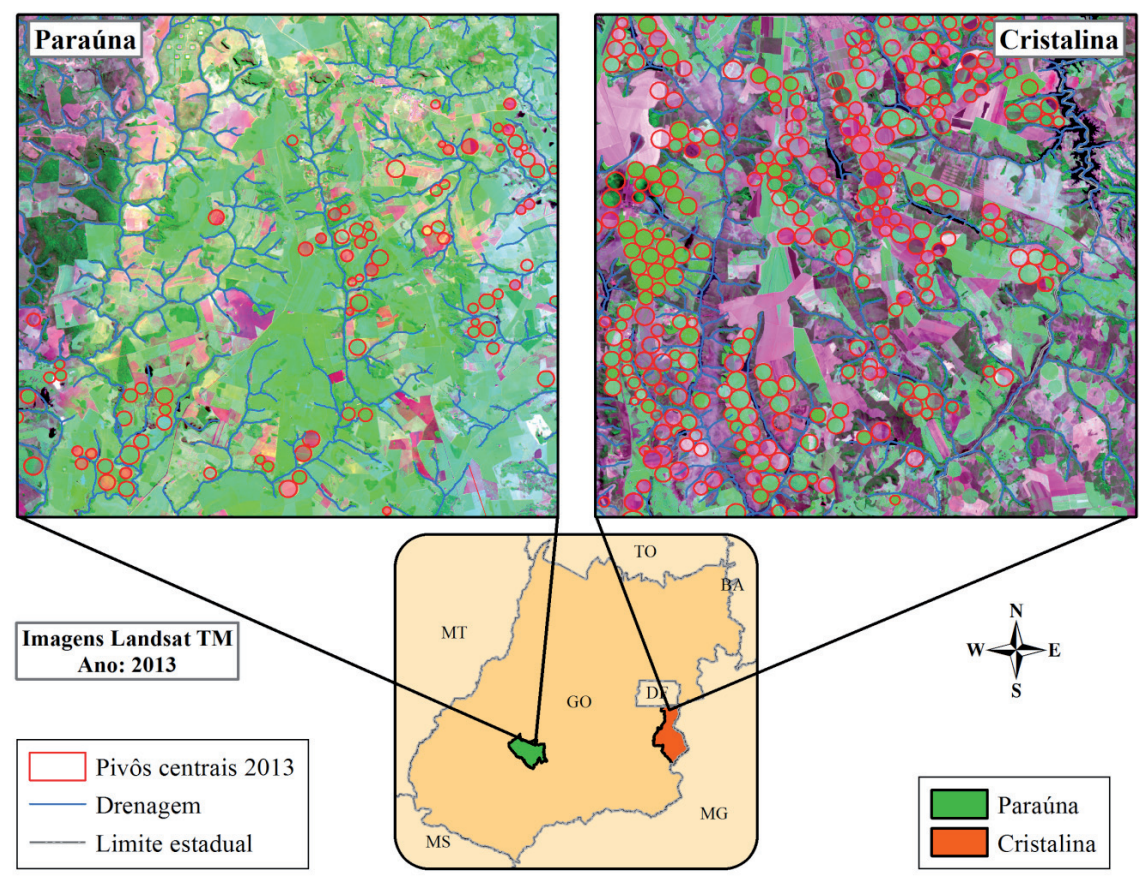

Figura 3 - Representação de áreas irrigadas nos municípios de Paraúna e de Cristalina Fonte: Goiás (2014c).

Cristalina é o município que mais apresentou trechos de alta demanda hídrica, em função de possuir o maior número de pivôs centrais instalados (659), o que lhe confere a terceira maior produção de grãos do estado, com uma safra de 1.447.837 toneladas em 2011, segundo levantamento do IMB (Goiás, 2013a). Já o município de Paraúna experimentou um aumento considerável na produção de grãos, passando de uma produção de 279.773 toneladas em 2011 para 555.567 em 2012 (Goiás, 2013a). Essas áreas representam dois diferentes cenários encontrados em Goiás. Na alta bacia do Rio Paranaíba, há uma grande quantidade de pivôs instalados e uma expansão mais moderada, enquanto no restante do território goiano a expansão ocorre de forma mais acelerada e os pivôs centrais ainda não são predominantes.

No que tange à demanda hídrica do estado, nos meses de janeiro, fevereiro, novembro e dezembro, conforme a Figura 4, ela não ultrapassa 
20\% do volume outorgável, o que torna esse período o menos preocupante, uma vez que apenas duas regiões de Goiás apresentaram demanda para irrigação em áreas onde existem pivôs centrais instalados. Uma delas foi a região nordeste, mais especificamente na bacia do Rio Paranã, que possui 30 equipamentos, com uma área total irrigada de 2.691 ha; e a outra, a sudeste, na bacia do Rio Aporé, ou do Peixe, que conta com três pivôs em uma área de 356 ha.

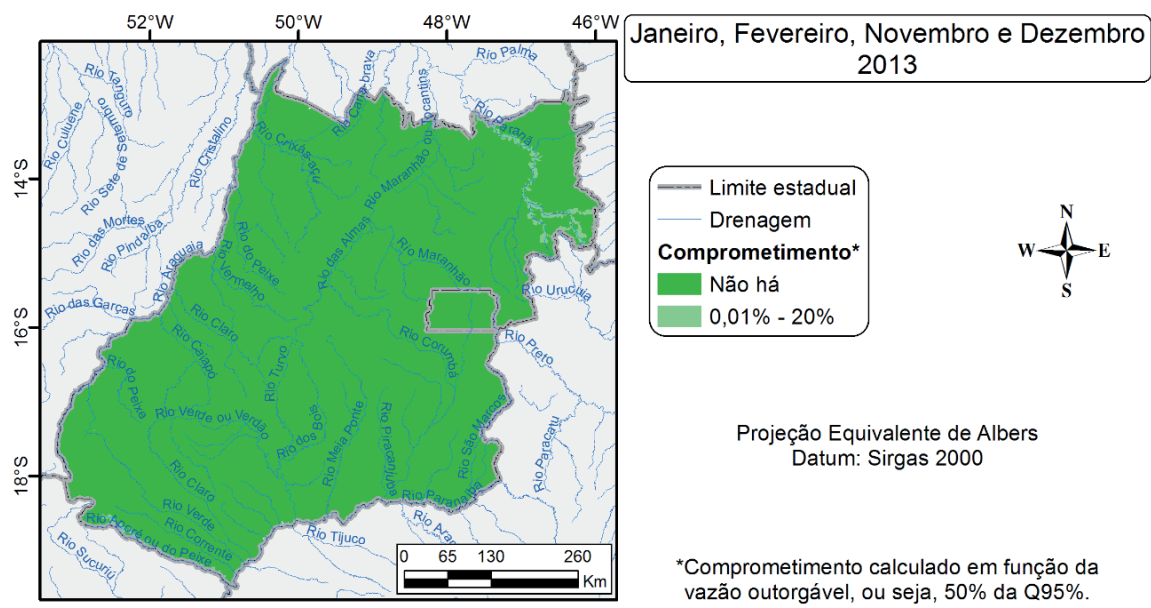

Figura 4 - Mapa representativo do comprometimento hídrico nos meses de janeiro, fevereiro, novembro e dezembro de 2013

Fonte: Elaborado pelos autores.

O mês de março, conforme pode ser visto na Figura 5 a seguir, é marcado por um declínio nos índices pluviométricos na região Centro-Oeste, e, em função disso, há um acréscimo das áreas que apresentam necessidade de irrigação. As áreas situadas no leste goiano apresentam maior demanda nesse mês, existindo basicamente dois trechos com alta demanda. O primeiro deles está situado na bacia do Rio Bezerra, que drena para o Rio Preto e possui 30 equipamentos instalados em uma área total de 2.513 ha, e o segundo está localizado na bacia do Rio Urucuia, que nasce em Goiás, drena para o estado de Minas Gerais até desaguar no Rio São Francisco, e possui 20 equipamentos instalados, com área total irrigada de 1.444 ha. Essas bacias já apresentam uma demanda por irrigação que chega a ultrapassar o volume máximo outorgável para captação direta. 


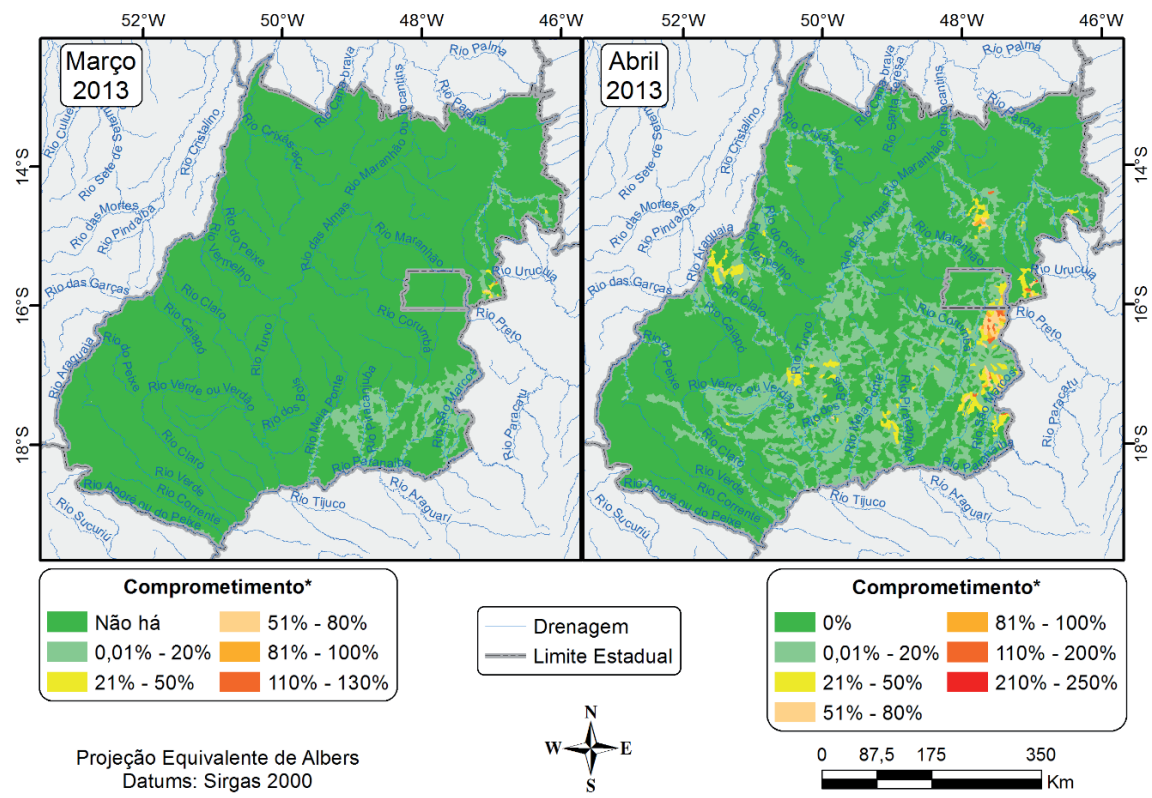

*Comprometimento calculado em função da vazão outorgável, ou seja, $50 \%$ da Q95\%.

Figura 5 - Mapa representativo do comprometimento hídrico nos meses de março e abril de 2013

Fonte: Elaborado pelos autores.

As regiões que apresentaram demanda no período de janeiro, fevereiro, novembro e dezembro a mantiveram no mês de março, com aumento gradual da necessidade hídrica. Na região sudoeste do estado, na bacia do Rio Paranaíba, os afluentes deste, situados a partir da bacia do Rio Meia Ponte para montante, já começam a apresentar demanda para irrigação, não ultrapassando a marca dos $20 \%$ do volume máximo outorgável para o mês de março.

Para o mês de abril, como mostra a Figura 5, nota-se que há uma generalização das demandas para irrigação na área de estudo e o surgimento de áreas com demanda superior ao volume máximo outorgável em diversas regiões do estado de Goiás, sobretudo nas nascentes do Rio São Marcos, do Ribeirão Ponte Alta e do Rio Veríssimo, afluentes diretos do Rio Paranaíba e situados no entorno do Distrito Federal e na região sudeste.

$\mathrm{Na}$ área do Distrito Federal, nota-se um incremento de demanda na bacia do Rio Preto, enquanto na região leste de Goiás há um incremento 
na demanda nas bacias dos rios Bezerra e Urucuia. No mês de abril surge também demanda na bacia do Rio Paranaíba, a jusante do Rio Meia Ponte até o Rio Claro, já na região sul do estado. No leste do estado, no município de Água Fria de Goiás, é possível notar uma demanda chegando a 110\% do volume outorgável. Entretanto, nessa região existe a lagoa da Jacuba, com área aproximada de $12,53 \mathrm{~km}^{2}$ e com capacidade para atender às demandas para irrigação da área, conforme um estudo particular realizado pela empresa Rhama Consultoria, Pesquisa e Treinamento Ambiental no ano de 2012. Vale salientar, no entanto, que esse estudo preconiza a realização do monitoramento da demanda pelo período de um ano, após o qual deveria ser feita uma revisão da capacidade da lagoa, o que até o presente momento não foi realizado. Diante desse fato, optou-se por preservar essa área como uma das que possuem elevado potencial de problemas hídricos, sobretudo pela necessidade de monitoramento.

Na bacia do Rio Araguaia, no noroeste goiano, a demanda surge nas áreas que drenam para o Rio do Peixe, no município de Montes Claros de Goiás, e mais intensamente na região entre o Rio Caiapó e Rio Crixás-Açu, no extremo noroeste do estado. Nesta existem 195 equipamentos, em uma área irrigada de 21.021 ha.

No mês de maio, quando efetivamente tem início o período de seca na região Centro-Oeste, há um incremento natural nas demandas para irrigação em todo o território goiano, conforme pode ser visto na Figura 6 a seguir. Esse aumento é mais acentuado na região do entorno do Distrito Federal e no médio Rio Araguaia, no município de Jussara, mais especificamente na bacia do Ribeirão Jurumirim e mais a montante na bacia do Córrego Dom Bill, já no município de Aragarças. Outras duas áreas que merecem destaque estão na bacia do Rio dos Bois, a primeira na parte central, sobretudo no Rio Turvo, e a segunda ao sul, nas bacias dos ribeirões Santa Bárbara e Bom Jesus.

O mês de junho é marcado pelo aumento natural da demanda de irrigação em todas as regiões que já demonstravam essa necessidade, com destaque para a do alto Rio Uru, que apresenta uma demanda significativa, já acima do volume máximo outorgável em alguns trechos. A jusante dessa área, é importante destacar, encontra-se o maior polo produtor de melancia de Goiás, região que responde por 73\% de toda a produção dessa fruta no estado (Goiás, 2014a). 


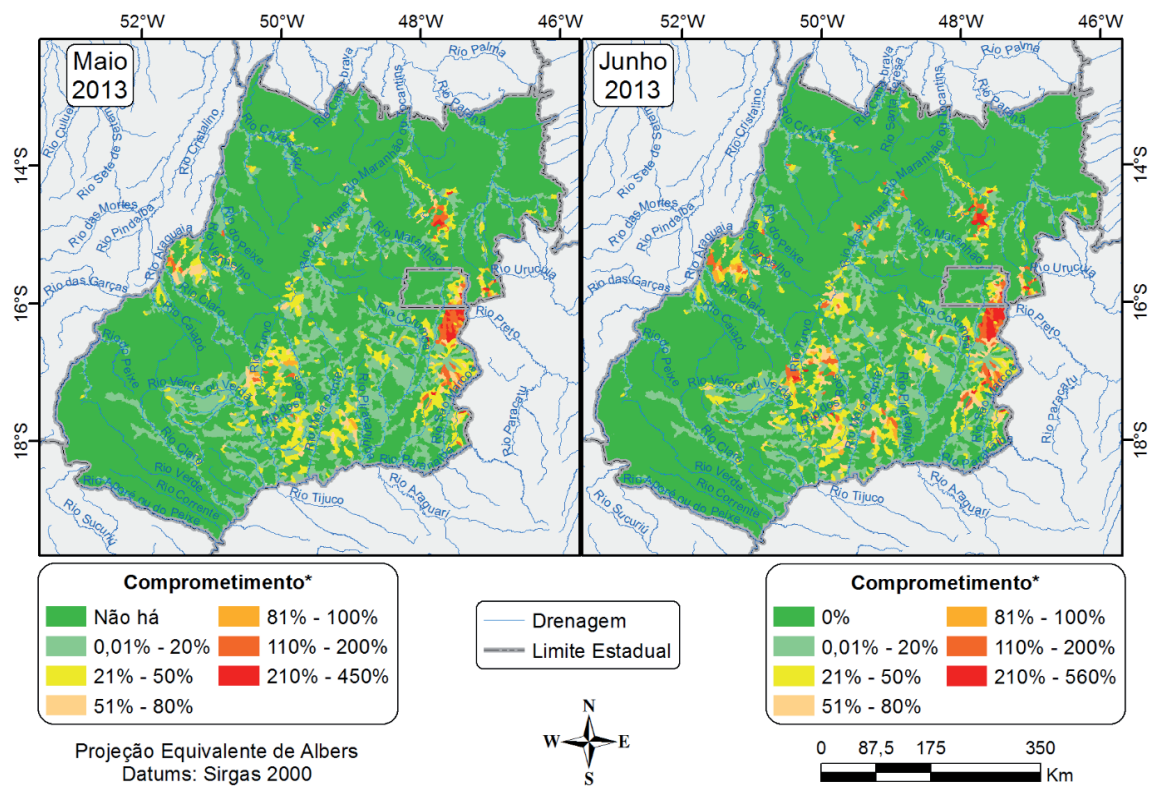

${ }^{*}$ Comprometimento calculado em função da vazão outorgável, ou seja, 50\% da Q95\%.

Figura 6 - Mapa representativo do comprometimento hídrico nos meses de maio e junho de 2013 Fonte: Elaborado pelos autores.

Nos meses de julho e agosto (Figura 7), nota-se um grande incremento na demanda hídrica para irrigação por pivôs centrais, o que eleva o volume máximo necessário até 7,6 vezes o volume outorgável no mês de julho e a 11 vezes no mês de agosto. É possível observar que a grande maioria das bacias que possuem pivôs instalados apresenta uma demanda superior ao volume outorgável para os referidos meses, sobretudo para o mês de agosto. No território do Distrito Federal há também aumento da demanda, o que intensifica o impacto sobre os recursos hídricos do estado de Goiás.

Nota-se que as áreas que apresentaram maior demanda situam-se predominantemente na bacia do Rio Paranaíba, partindo do Rio Claro para montante até as nascentes do Rio São Marcos. Vale ressaltar ainda que a região do alto Paranaíba apresenta um grande número de pivôs centrais instalados no estado de Minas Gerais, onde Guimarães e Landau (2011) mapearam 1.013 equipamentos, com uma área total de 74.330 ha 
para o ano de 2010. Somam-se a esses mais 2.141 equipamentos mapeados no estado de Goiás, com área total de 151.604 ha Irrigados, conforme dados do IMB (Goiás, 2014c), o que perfaz um total de 3.154 equipamentos e área irrigada de 225.934 ha nessa bacia.

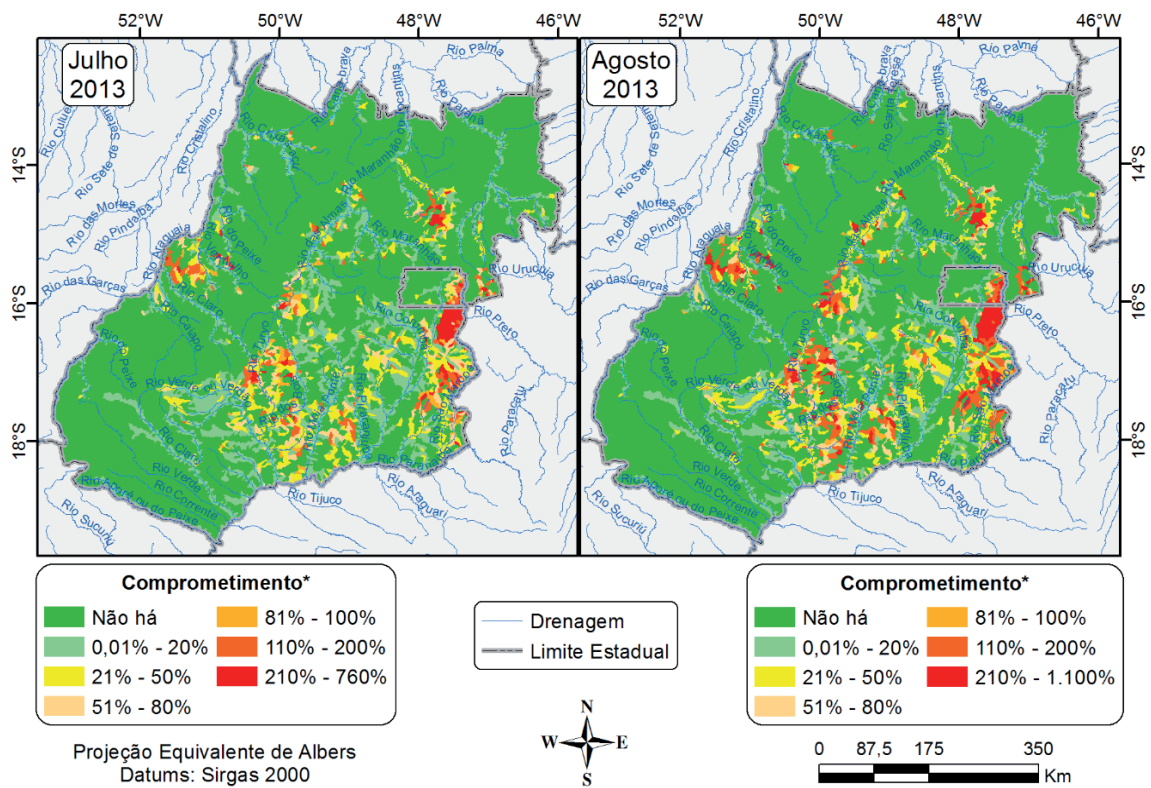

*Comprometimento calculado em função da vazão outorgável, ou seja, $50 \%$ da Q95\%.

Figura 7 - Mapa representativo do comprometimento hídrico nos meses de julho e agosto de 2013

Fonte: Elaborado pelos autores.

O mês de setembro (Figura 8) é o que apresenta a maior demanda de irrigação, quando se chega a requerer um volume 14 vezes superior ao máximo outorgável. Há uma predominância de demanda acima de 50\% do volume outorgável tanto no território goiano quanto no Distrito Federal. Esse é, indubitavelmente, o mês mais crítico do ano, no que tange à irrigação por pivôs centrais.

A partir do mês de outubro, com o início do período chuvoso, as demandas começam a diminuir, passando a predominar as que estão abaixo de $20 \%$ do volume máximo outorgável. Vale salientar que ainda existem áreas com demanda acima do outorgável, sobretudo nas bacias dos rios 
São Marcos e Veríssimo. Na região de Jussara, a demanda fica em torno de 20 a $50 \%$ do volume outorgável.

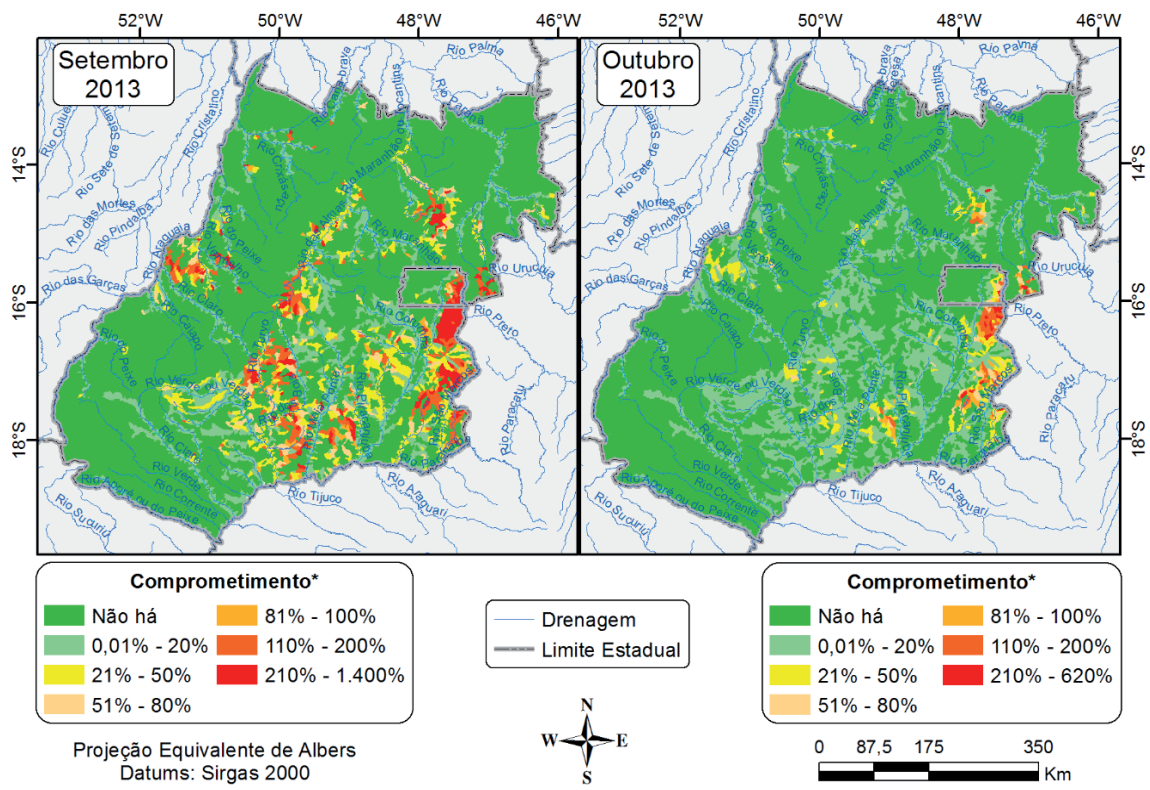

*Comprometimento calculado em função da vazão outorgável, ou seja, 50\% da Q95\%.

Figura 8 - Mapa representativo do comprometimento hídrico nos meses de setembro e outubro de 2013

Fonte: Elaborado pelos autores.

Considerações finais

O principal ponto a ser evidenciado neste estudo é a relação dos pivôs centrais com os usos a jusante. A legislação estadual preconiza a análise do uso apenas a montante, e este trabalho evidencia que é indispensável a análise do impacto também a jusante, para determinar o real comprometimento desses equipamentos de irrigação. Não foi objeto deste estudo determinar as áreas onde há falta de água, pois o que se objetivou foi estabelecer um parâmetro de partida para análises futuras, com a integração de novos usos e modelos referentes aos barramentos e a outras intervenções que visam melhorar a disponibilidade hídrica. Além disto, é importante ressaltar que a geração hidroelétrica e o consumo energético 
para irrigação são pontos nevrálgicos do setor agrícola, sendo necessário, ainda, determinar o quanto a disponibilidade energética incentiva ou limita a expansão da irrigação.

O estado de Goiás não possui, atualmente, uma rede de monitoramento de vazões, e, por isso, os dados utilizados provieram de estações de monitoramento que estão instaladas em grandes bacias, o que dificulta a análise mais acurada da situação hídrica do estado, que tem uma drenagem marcada por rios de primeira e de segunda ordem. Como a falta de monitoramento está atrelada à carência de estudos mais aprofundados acerca dos recursos hídricos de domínio goiano, é necessário um ponto de partida que possibilite intervenções em áreas que já se encontram com problemas ou na iminência de vir a tê-los.

Neste sentido, este trabalho consegue, portanto, determinar quais são as áreas prioritárias e também os meses mais críticos no que tange à demanda para irrigação por pivôs centrais. Desta forma é possível orientar os investimentos públicos e as ações das políticas estaduais de recursos hídricos.

O principal obstáculo para a elaboração de balanços hídricos e também para a gestão de recursos hídricos em Goiás é a falta de dados primários que possibilitem a geração de informações confiáveis. Não foi foco deste estudo a substituição dos métodos de monitoramento, pois o que se pretende é que as áreas críticas sejam tratadas como prioridade no momento em que ações de monitoramento e fiscalização forem empreendidas.

Um ponto importante a ser ressaltado é que, para o cálculo da demanda, considerou-se neste trabalho que todas as captações são diretas. Sabe-se, entretanto, que vários equipamentos captam água em barramentos. Porém, como os dados referentes à capacidade de suporte dessas acumulações não estão disponíveis, não é possível afirmar que esses reservatórios realmente acumulam volume suficiente para atendimento dos pivôs centrais e da vazão a jusante. Assim, como já mencionado, deve-se analisar a efetiva capacidade desses barramentos nas áreas críticas, de modo a melhor ajustar os resultados obtidos. Sabe-se que essa é uma tarefa nada trivial e bastante dispendiosa, portanto, essa delimitação inicial permitirá o melhor emprego de recursos, uma vez que as áreas que necessitam de análise urgente estão mapeadas. Diante do exposto, este trabalho poderá ser utilizado como direcionamento para futuras análises e como suporte para a implementação de políticas públicas consoantes com os princípios de economicidade e da razoabilidade. 


\section{Referências}

BRASIL, Agência Nacional de Águas. Hidroweb, Sistema de Informações Hidrológicas. Agência Nacional de Aguas (ANA), Brasília, 2006. Disponível em: http://hidroweb.ana.gov.br/. Acesso em: 10 jan. 2014.

. Lei $\mathrm{n}^{\mathrm{0}}$ 9.433, de 8 de janeiro de 1997. Institui a Política Nacional de Recursos Hídricos, cria o Sistema Nacional de Gerenciamento de Recursos Hídricos, regulamenta o inciso XIX do art. 21 da Constituição Federal e altera o art. $1^{\circ}$ da Lei $n^{\circ} 8.001$, de 13 de março de 1990, que modificou a Lei $n^{\circ} 7.990$, de 28 de dezembro de 1989. Brasília, 1997.

. Ministério do Meio Ambiente. Agência Nacional de Águas (ANA). Conjuntura dos Recursos Hídricos no Brasil - 2013. Brasília, 2013.

CLARKE, R.; KING, J. The water atlas. Nova York: New Press, 2004.

DASTANE, N. G. Effective Rainfall in Irrigated Agriculture. FAO Irrigation and Drainage Paper, n. 25. Rome: FAO, 1978.

EITEN, G. Cerrado's vegetation. In: PINTO, M. N. (Org.). Cerrado: caracterização, ocupação, e perspectivas. 2. ed. Brasília: Ed. UnB, 1993. p. 17-73.

FRAITURE, C. F.; WICHELNS, D. Satisfying future water demands for agriculture. Agricultural water Management 97, p. 502-511, 2010.

GOIÁS. Secretaria de Gestão e Planejamento do Estado de Goiás. Instituto Mauro Borges de Estatísticas e Estudos Socioeconômicos. Produto Interno Bruto dos municípios goianos 2011. Goiânia: IMB, 2013a. Disponível em: <http://www. seplan.go.gov.br/sepin/pub/pib/pibmun2011/pibmun2011.pdf $>$. Acesso em: 21 maio 2014.

. Secretaria de Gestão e Planejamento do Estado de Goiás. Instituto Mauro Borges de Estatísticas e Estudos Socioeconômicos/ Banco de Dados Estatísticos (BDE). Goiânia: IMB, 2014a. Disponível em: < http://www.seplan.go.gov.br/sepin/ bde/>. Acesso em: 23 maio 2014.

. Secretaria de Gestão e Planejamento do Estado de Goiás. Instituto Mauro Borges de Estatísticas e Estudos Socioeconômicos. Goiás no contexto nacional 2013. Goiânia: IMB, 2014b. Disponível em: <http://www.seplan.go.gov.br/sepin/ down/goiascn2013.pdf>. Acesso em: 3 jul. 2014.

Secretaria de Gestão e Planejamento do Estado de Goiás. Instituto Mauro Borges de Estatísticas e Estudos Socioeconômicos. Mapeamento das Áreas Irrigadas por Pivôs Centrais no Estado de Goiás. Informe Técnico $\mathrm{n}^{\circ}$ 1. Goiânia: IMB, 2014c. Disponível em: <http://www.seplan.go.gov.br/ sepin/pub/informestecnicos/1-Mapeamento\%20das\%20\%C3\%81reas\%20 Irrigadas\%20por\%20Piv\%C3\%B4s\%20Centrais\%20no\%20Estado\%20de\%20 Goi\%C3\%A1s-201401.pdf>. Acesso em: 15 maio 2014.

. Secretaria de Infraestrutura (Seinfra). Balanço energético do Estado de Goiás 2013. Goiânia: Seinfra, $2013 b$.

. Secretaria do Meio Ambiente e dos Recursos Hídricos (Semarh). Conselho Estadual de Recursos Hídricos (CERHi). Resolução $n^{o}$ 9, de 4 de maio de 2005. 
Estabelece o Regulamento do sistema de outorga das águas de domínio do estado de Goiás e dá outras providências. Goiânia: CERHi, 2005. Disponível em: < http:// www.semarh.goias.gov.br/site/conteudo/legislacao-de-recursos-hidricos $>$. Acesso em: 31 jan. 2014.

. Secretaria do Meio Ambiente e dos Recursos Hídricos (Semarh). Manual Técnico de Outorga. Goiânia: Semarh, 2012. Disponível em: <http://www. semarhtemplate.go.gov.br/uploads/files/manual_outorga/manual_tecnico_de_ outorga_versao_01.pdf>. Acesso em: 2 jan. 2014.

GUEDES FILHO, Ernesto Moreira Guedes (Org.). Setor Elétrico Brasileiro: cenários de crescimento e requisitos para a retomada de investimentos. Estudo contratado pela Câmara Brasileira de Investidores em Energia Elétrica (CBIEE). São Paulo, 2003.

GUIMARÃES, D. P.; LANDAU, E. C. Mapeamento das áreas irrigadas por pivôs centrais no Estado de Minas Gerais. Boletim de Pesquisa e Desenvolvimento. Sete Lagoas: Embrapa Milho e Sorgo, 2011.

IBGE. Instituto Brasileiro de Geografia e Estatística. Geografia do Brasil. Rio de Janeiro: IBGE, 1988.

. Instituto Brasileiro de Geografia e Estatística. Censo demográfico 19402010. Rio de Janeiro: IBGE, 2010. Disponível em: <http://seriesestatisticas.ibge. gov.br/series.aspx?vcodigo=POP122>. Acesso em: 14 abr. 2014.

. Instituto Brasileiro de Geografia e Estatística. Produto Interno Bruto dos Municípios 2010. Rio de Janeiro: IBGE, 2012.

MARCUZZO, F; FARIA, T. G; PINTO FILHO, R. de F. Chuvas no estado de Goiás: análise histórica e tendência futura. Acta Geográfica. Boa Vista, v.6, n.12, mai/ago 2012. p. 125-137, 2012.

NASCIMENTO, M do. Geomorfologia do estado de Goiás. Boletim Goiano de Geografia, Goiânia, v. 12, n. 1, p. 1-22, 1992.

RODRIGUES, G. C.; PEREIRA, L. S. Assessing economic impacts of deficit irrigation as related to water productivity and water costs. Biosystems Engineering, Ed. Elsevier, v. 103, p. 536-551, 2009.

ONU. Organização das Nações Unidas. Fundo de População das Nações Unidas/ Divisão de Informações e Relações Externas (UNFPA). Relatório sobre a Situação da População Mundial 2011. UNFPA, 2011.

. Organização das Nações Unidas para Alimentação e Agricultura (FAO). Water uses. FAO, 2014. Disponível em: <http://www.fao.org/nr/water/aquastat/ water_use/index.stm>. Acesso em: 13 abr. 2014.

SMITH, M. Manual for CROPWAT version 5.2. Rome: FAO, 1988.

TEIXEIRA NETO, A. Pequena história da agropecuária goiana (O ouro acabou? Viva o boi!/O ouro se foi? Chegou o boi!). Revista Educação \& Mudança, Anápolis, GO, n. 20, 21, p. 9-42, 2013.

TUCCI, C. E. M.; HESPANHOL, I.; CORDEIRO NETTO, O. de M. Cenários da gestão da água no Brasil: uma contribuição para a "visão mundial da água". 
Revista Brasileira de Recursos Hídricos, Porto Alegre, v. 5, n. 3, jul./set. p. 31-43, 2000.

VARIS, O. Right to water: the millennium development goals and water in the MENA region. International Journal of Water Resources Development, v. 23, n. 2, p. 243-266, 2007.

Lindolfo Caetano Pereira Júnior - Possui graduação em Tecnologia em Geoprocessamento pelo Instituto Federal de Educação, Ciência e Tecnologia de Goiás. Atualmente é pesquisador em geoprocessamento na Secretaria de Estado de Gestão e Planejamento de Goiás.

Patrícia Pereira da Silva Nicácio - Possui graduação em Geoprocessamento pelo Instituto Federal de Educação, Ciência e Tecnologia de Goiás e em Administração pela Universidade Federal de Goiás. Atualmente é pesquisadora em geoprocessamento no Instituto Mauro Borges de Estatísticas e Estudos Socioeconômicos de Goiás.

Recebido para publicação em 17 de agosto de 2014 Aceito para publicação em 2 de outubro de 2014 